\title{
Management and Research Applications of Long-range Surveillance Radar Data for Birds, Bats, and Flying Insects
}

\author{
Janet M. Ruth, Jeffrey J. Buler, Robert H. Diehl, and Richard S. Sojda
}

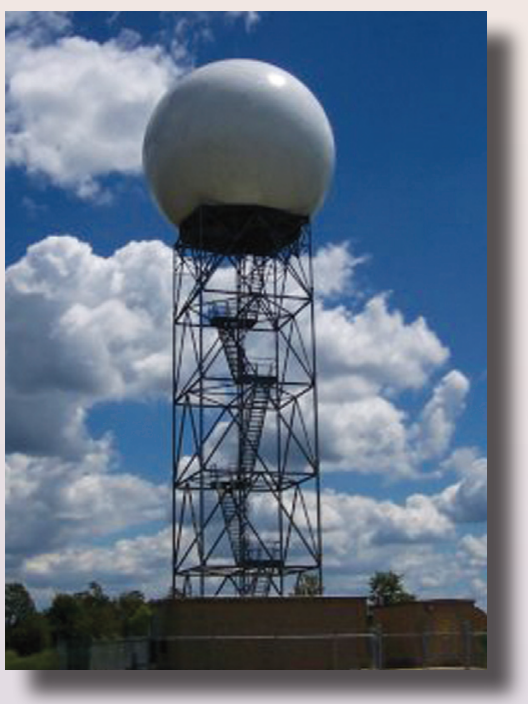

\section{What are long-range surveillance radars?}

Long-range surveillance radars include weather-surveillance radars, airport-surveillance radars, terminal Doppler weather radars, and private Doppler radars. All of these technologies can be used to study bird, bat, and insect movement patterns. However, with the exception of the weather-surveillance radar system in the United States, access to data from these radars is currently limited. Therefore, we focus this publication on applications of the U.S. weather-surveillance system.

The current nationwide system of more than 150 digital Doppler weather surveillance radars, variously known as WSR-88D (Weather Surveillance Radar, 1988 Doppler) or NEXRAD (NEXt generation RADar), is the most well known network of long-range surveillance radars. WSR-88D is also the long-range radar most frequently applied to biological questions. These high-powered and highly sensitive radars repeatedly scan a wide geographic area at multiple elevation angles using a narrow conical beam, providing coarse spatial and temporal resolution. WSR-88D measures three data products that are useful for biological applications: (1) reflectivity, a measure of the amount of energy returned to the radar from targets in the sampled airspace, (2) radial velocity, a measure of mean target velocity toward or away from the radar, and (3) spectral width, a measure of variation in radial velocity. The maximum detection range

\section{7 here is renewed interest in using long-range surveillance radar as a biological \\ research tool due to substantial improvements in the current network of radars} within the United States. These improvements include an enhanced capacity to detect biological targets and Doppler capability that enables the measurement of direction and speed of targets. Additionally, the digital nature of the radar data, plus the increasing availability of inexpensive computing power and geographic information systems, enables a broad range of quantitative, spatially explicit biological applications.

The purpose of this publication is to provide a summary of long-range surveillance radar technology and applications of these data to questions about movement patterns of birds and other flying wildlife based on publications that provide more detailed information (Buurma, 1995; Gauthreaux and Belser, 2003a, b; Gauthreaux and others, 2003; Diehl and Larkin, 2005; Larkin, 2005). For simplicity we refer primarily to birds in this publication; however, the applications are usually also appropriate for bats and flying insects. The intended audience is potential radar-data end users, including natural-resource management and regulatory agencies, conservation organizations, and industry. for WSR-88D data typically varies depending on the altitude of birds in the airspace (fig. 1). When these data are used to answer questions related to habitat use (for example, when birds are low to or just taking off from the ground) the maximum detection range is usually less than $100 \mathrm{~km}$ (62 mi). The maximum range increases when these data are used to answer questions about migrating birds at cruising flight altitudes. Data can provide information about bird movement patterns at scales that range from a few kilometers (Diehl and

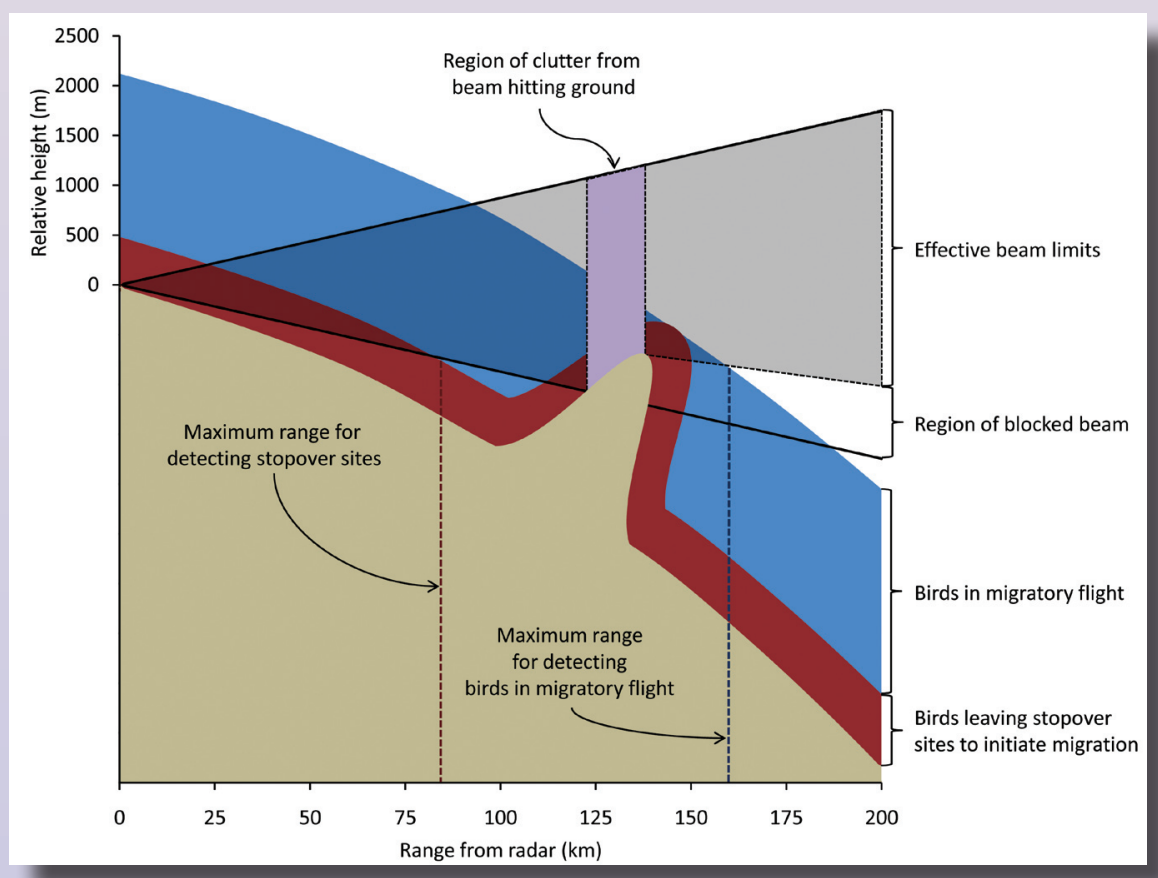

Figure 1. Height profile of a radar beam in standard atmospheric conditions at the lowest elevation angle $\left(0.5^{\circ}\right)$. Solid black lines denote the theoretical beam limits. The tan area denotes the curve of the earth and topographic features. The maximum detection range occurs where the effective radar beam begins to completely pass over targets. 
Larkin, 2005), to entire continents (Gauthreaux and others, 2003) when combining data from an entire network of radars.

Long-range surveillance radar provides valuable data that can be applied to addressing biological questions, and upgrades already in progress will improve these applications. However, it is important to recognize the strengths and weaknesses of WSR-88D, understand that it is one potential tool in a much larger toolbox, and recognize that it does not necessarily replace more traditional field observations. Validating data from longrange radar through use of complementary methods is extremely important. Finally, although most long-range radars are maintained and operated by experts in government agencies, application of this technology to biological issues does require people experienced in analysis to ensure that its results are correctly interpreted and applied. The intuitive visual appeal of these data (fig. 2) conceals the challenging analytical issues that often need to be addressed in order to quantify the data.

\section{Strengths of WSR-88D}

- Well suited to studying bird distributions and movements aloft, and their responses to factors that affect their distributions and movements, across large spatial extents and temporal scales.

- Extensive network with individual radars identical in design to each other, simplifying system-wide applications. Although some local parameters do vary by radar, measures of reflectivity are standardized across radars.

- Provides data about bird movement patterns in remote areas that are difficult to access. It may be more cost effective than implementing large-scale field data collection, especially for answering questions posed over large spatial extents or in cases where a relatively small field dataset can be used to calibrate or corroborate a more extensive radar dataset. In addition, WSR-88D data can provide initial information to focus future sitespecific studies and on-the-ground field work.

- Operates continuously across the country. A comprehensive dataset of nearly every radar sweep, taken every 4.5 to 10 minutes (prior to 2008 the frequency was 6-10 minutes), for every WSR-88D site dating back to the mid-1990s is archived and freely available, enabling long-term research across the United States.

\section{Limitations of WSR-88D}

- Recent improvements (starting in 2008) have increased spatial resolution severalfold (for example, sampling a 2-dimensional space of about $250 \mathrm{~m} \times 250 \mathrm{~m}$ at $30-\mathrm{km}$ range [820 $\mathrm{ft} \times 820 \mathrm{ft}$ at 18 -mi range]); data prior to 2008 are available at lower resolution (about $500 \mathrm{~m}$ x $1,000 \mathrm{~m}$ at $30 \mathrm{~km}[1,640 \mathrm{ft}$ x $3,280 \mathrm{ft}$ at 18 $\mathrm{mi}]$ ). Regardless, the resolution of WSR-88D data is still rather coarse and is usually not well suited for studying movement patterns at finer spatial scales or answering site-specific questions. Site-specific applications are best addressed using short-range radar systems that collect very fine resolution data. However, WSR-88D can provide an initial, coarse index of activity in places where the radar is suitably located relative to the site of interest.

- Target identification remains a challenge in analyzing WSR-88D data. Echoes originate from precipitation, dust, ground clutter, birds, bats, insects, and other sources. Even when nonbiological targets have been filtered out, the remaining biological targets can be difficult to distinguish from each other. Although there are several generally accepted means of separating out insectlike targets, the data almost invariably include some insects. Except in certain circumstances, there is no widely accepted way of distinguishing bats from birds. The presence of insects or bats in "birdlike" radar data can bias analyses of both reflectivity and velocity data. It is because of this challenge that complementary use of other measures is needed to determine target identity.

- The locations of WSR-88D radars are fixed and may not provide effective coverage for particular areas. Data nearest the WSR-88D radar (approximately 10-20 km [6-12 mi]) may be unusable due to ground clutter caused by physical structures such as tall buildings and bridge overpasses. Lack of effective coverage may also occur if a location of interest is too far from the radar site or the radar beam over the location is partially or completely blocked by relief in terrain (fig. 1). For example, in the Rocky Mountain West, substantial portions of the radar coverage around some radars are obstructed by mountain ranges, especially at the lowest elevation angles.

- WSR-88D is not well suited to detecting low-flying birds and is poor at resolving the height at which birds fly.

However, if these limitations are addressed and the data are used appropriately, WSR-88D data can provide valuable information to managers, regulators, conservationists, and researchers.

\section{For what purposes can long-range surveillance radar data be used?}

Combining the radar-reflectivity and radial-velocity data with knowledge of radar beam geometry yields quantitative information about the density, speed, direction, altitude, and location of animals aloft.

- WSR-88D can provide information about bird movement patterns at broad spatial and temporal scales. This can help us understand how migrants respond to weather (hurricanes, for example), and physical obstacles (large bodies of water, mountain ranges, deserts); how bird movement patterns are associated with habitat; and how bird movement patterns, habitat use, or numbers are affected by management practices at broad spatial scales such as wetland restoration or Conservation Reserve Program acreage.

- Where WSR-88D radars provide effective coverage and if there are no radar beam obstructions, they can be useful in identifying important migrant stopover sites (fig. 2), locating roost sites, and documenting localized movement patterns. This information can be valuable in identifying important habitat for protection and movement patterns of species of management concern such as waterfowl or blackbirds.

- Data from the entire network of WSR$88 \mathrm{D}$ radars (or some subset) can be used to monitor migration patterns at a regional or national scale, making it possible to look at seasonal and annual variation.

- Archived WSR-88D data can be useful for assessing long-term changes in movement patterns or bird distributions in response to altered landscapes, habitats, and ecological communities due to factors such as agricultural practices, climate change, urbanization, exotic and invasive species, and habitat loss.

- WSR-88D data can be used in bird/aircraft collision risk assessment. The U.S. Air Force, through its Avian Hazard System, uses WSR-88D data to monitor bird activity in low-level airspaces.

\section{How much will it cost?}

The costs associated with using WSR88D data to address bird management and conservation questions will vary substantially, depending on the research question. Providing comparative estimates is beyond the scope of this publication. However, we will attempt to summarize the major cost components involved. There is free access to WSR-88D data, but these data are difficult to parse and analyze, expertise is scarce, and the process can require substantial database-storage space and complex computing capacity. Therefore, the major expenses for a research project using WSR-88D data are similar to those for other remote-sensing data applications, including:

- Labor for screening, interpreting, and analyzing data

- Support to acquire, maintain, and(or) update large, complex computing capacity 

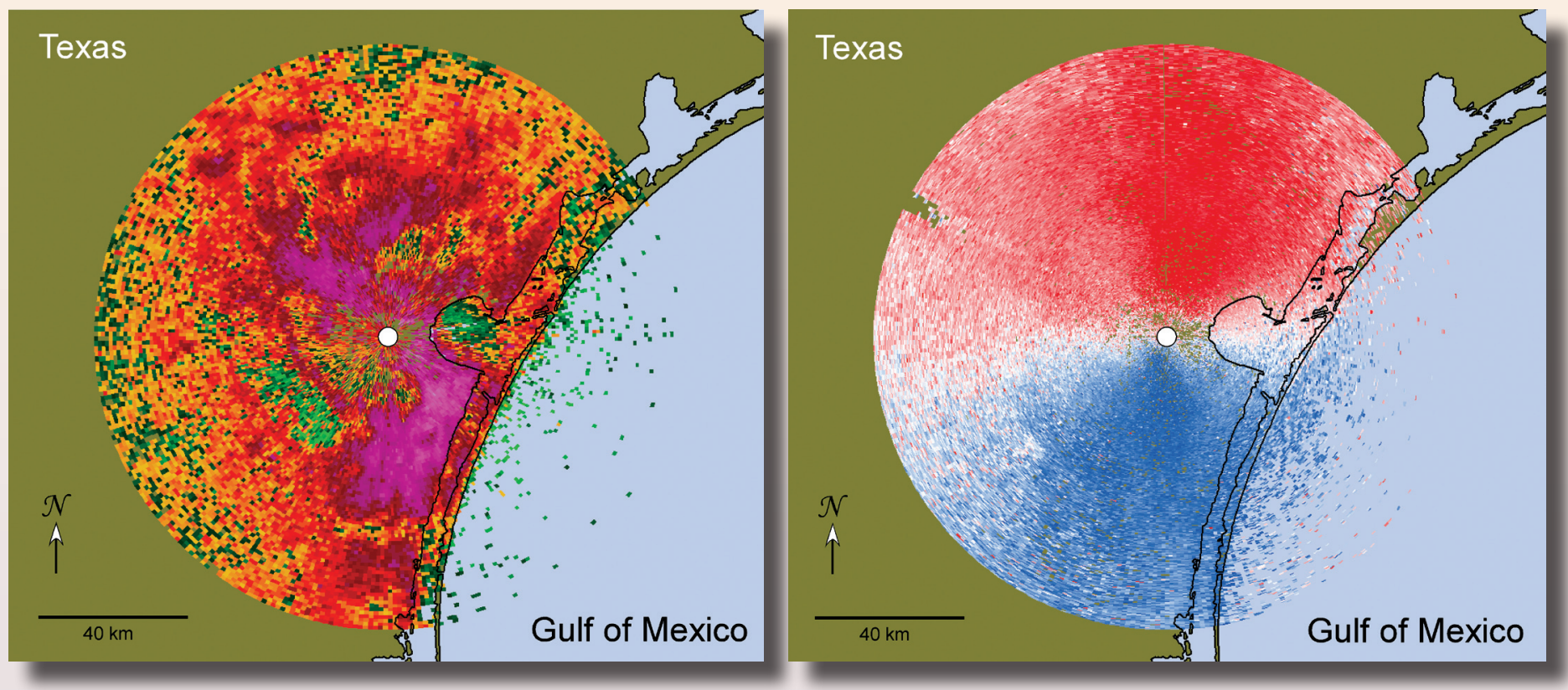

Figure 2. (Left) Radar reflectivity of birds during the onset of nocturnal migration near Corpus Christi, Texas, on May 14, 2005, at 7:34 p.m. CST. A white dot marks the location of the radar. Different colors indicate differences in the density of birds aloft, where purples and pinks represent high densities. Spatial variation in reflectivity (color) shortly after birds take flight reflects how birds were distributed in the landscape just prior to flight. Using this association, data from these radars can identify important stopover habitat. (Right) Radial velocity of birds on the same date about 2.5 hours after the onset of migration. Blue indicates movement toward the radar, red away, showing that overall direction of flight is almost due north.

- Possible collection of ancillary field data for calibration or corroboration of radar measures

- Development of new methods to reduce known sources of bias in radar measures and(or) apply computing techniques (for example, artificial intelligence) to replace current labor-intensive analyses

The end user can choose a low-cost approach, which produces a cursory, qualitative result that may effectively answer simpler types of research questions, or a higher-cost approach to provide more rigorous, quantitative answers, which requires more complex analyses, field-data collection, and(or) development of new methods of analysis. It is crucial that the end user clearly define the research or management questions in order to know where along this continuum the answers to their questions lie. In general, the cost of research increases with the size of the area or length of time being studied or with the complexity of the question being asked.

\section{What methods can be used to calibrate or validate long-range surveillance radar data?}

The importance of using complementary methods to calibrate or validate long-range radar data can not be overemphasized. Gathering such data enables us to verify the interpretations of long-range surveillance radar data. This may involve:

- Coordinated use of portable short-range radars, including vertically-pointing, fixedbeam radars
- Integration with landcover maps (for example, Landsat) and other geospatial data layers

- On-the-ground methods such as thermal imagery, acoustic monitoring, mist netting/ bird banding, bird surveys (point counts), visual observations

- Telemetry

- Expert knowledge about bird (and other biological target) distribution, behavior, and timing of migration, to further inform radar data that are not species or taxa specific

\section{How can my agency/organization take advantage of this technology?}

If you think radar technology might be useful in addressing your management, regulatory, conservation, or operating question, you should become an "educated consumer." Read up on the materials provided on the Radar Technology Web site (http://www.fort. usgs.gov/radar) and other resources before contacting potential collaborators to discuss your information needs and the technologies available to address those needs. We do not suggest that managers, regulators, or conservationists need to become experts in accessing and analyzing WSR-88D (or other radar) data; there are many opportunities to work with collaborators who have this expertise.

\section{What information do I as a manager or regulator need to provide?}

Collaboration and communication among the team made up of end users (man- agers, regulators, conservationists, industry), biological researchers, and experts in accessing, analyzing and interpreting radar data is crucial to developing the approach that truly answers the questions being asked by the end users. The most important thing for potential users to do in preparing to talk with a scientist about radar applications is to identify their highest priority issue and develop a clear and specific description of the priority management, regulatory, conservation, or operating question(s) that they are trying to answer. The more details a user can provide about exactly what information is needed and why it is important, the easier it will be for a potential collaborating scientist to help design a research project using the appropriate radar technology and(or) other methods that will answer his or her questions. For example, do you want to know the relative abundance of birds using a stopover habitat? The passage rates over a given area? The prevalence of roosts near an airport? The foraging behavior of waterfowl? Do you need to know what species they are? What is the spatial and temporal extent of the question? Is your question sitespecific? What is the nature of the landscape (homogenous, mountainous) involved?

\section{Whom can I contact with questions? Who are my potential collaborators?}

There are numerous opportunities for partnership in developing projects to apply radar technologies to address management, regulatory, and conservation questions. Some potential contacts are provided on the Radar 
Technology Web site by going to the Radar Workshop Participants List (http://www.fort usgs.gov/radar/workshop_participants.asp) or by going to information on USGS Radar Research (http://www.fort.usgs.gov/radar/ USGSResearch.asp) or Related Resources (http://www.fort.usgs.gov/radar/resources. asp); however, this information is by no means comprehensive. There are scientists working for Federal agencies, universities, conservation groups, and private contractors with whom you can collaborate. An internet search using combinations of words such as "radar," "WSR-88D," "NEXRAD," "bird," "avian," and "ornithology" will produce additional information and potential collaborators. However, application of radar technology to wildlife-resource issues remains a developing science requiring peer review. The importance of being an educated consumer can not be over-emphasized. The USGS does not generally endorse other particular organizations or products for WSR-88D radar analysis; however, we do collaborate extensively with others and we have a duty to promote the best science available. End users should inform themselves about the technology, clearly identify their management or research questions, evaluate the programs, products, and peer-reviewed publications produced by potential collaborators, talk with scientists and ask probing questions. You are welcome to contact the authors of this document, or any of the scientists listed among the workshop participants.

\section{Key References}

Several of these publications are available online (titles bolded) through the Radar Biology Bibliographies (http://www.fort.usgs. gov/radar/bibliography.asp) on the Radar Technology Web site.

Buurma, L.S., 1995, Long-range surveillance radars as indicators of bird numbers aloft: Israel Journal of Zoology, v. 41, p. 221-236.

Diehl, R.H., and Larkin, R.P., 2005, Introduction to the WSR-88D (NEXRAD) for ornithological research, in Ralph, C.J., and Rich, T.D., eds., Bird conservation implementation and integration in the Americas, Proceedings of the Third International Partners in Flight Conference, Vol. 2: Albany, Calif., USDA Forest Service, Pacific Southwest Research Station, General Technical Report PSW-GTR-191, p. 876-888.

Eastwood, E., 1967, Radar ornithology: London, UK, Methuen Publishing Ltd., 278 p.

Gauthreaux, S.A., Jr., and Belser, C.G., 2003a, Overview-Radar ornithology and biological conservation: Auk, v. 120, p. 266-277.
Gauthreaux, S.A., Jr., and Belser, C.G., 2003b, Bird movements on Doppler weather surveillance radar: Birding, v. 35 , p. 616-628.

Gauthreaux, S.A., Jr., Belser, C.G., and van Blaricom, D., 2003, Using a network of WSR-88D weather surveillance radars to define patterns of bird migration at large spatial scales, in Berthold, P., Gwinner, E. and Sonnenschein, E., eds., Avian migration: Berlin, Germany, Springer-Verlag, p. 335-346.
Larkin, R.P., 2005, Radar techniques for wildlife, in Braun, C.E., ed., Techniques for wildlife investigations and management, 6th edition: Bethesda, Md., The Wildlife Society, p. 448-46

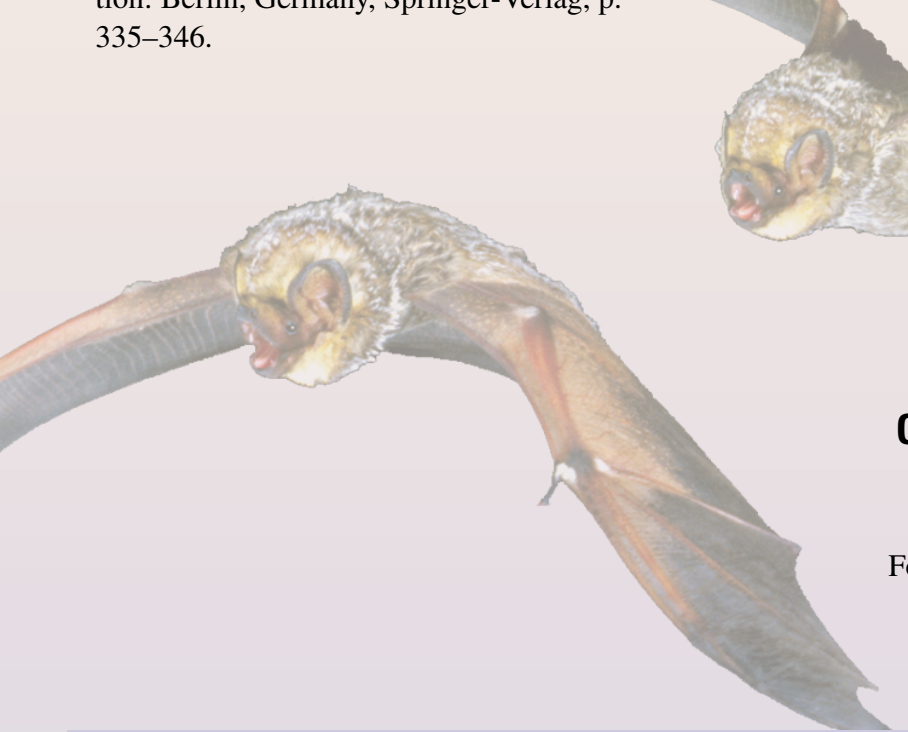

\section{Contact Information:}

Janet M. Ruth

U.S. Geological Survey

Fort Collins Science Center Arid Lands Field Station janet_ruth@usgs.gov

\section{Some Additional Information and Online Resources}

Radar data are archived at the National Climatic Data Center (NCDC). They can be downloaded free with the NEXRAD Inventory Search Tool and viewed using the Weather and Climate Toolkit. The Toolkit can also export data from its unique binary format to a variety of GIS-friendly formats (shapefile, tif). Links to several free visualization and analysis products are provided below. If you choose to delve into these resources, you will be confronted by terminology (for example, Level II and Level III data) that is beyond the scope of this publication. You will either need to do extensive research or consult with experts to understand the terminology, analyses, and interpretation.

\section{Unfiltered Real-Time Radar Images}

Current images and loops -

http://radar.weather.gov

Current images and regional composite loops -

http://whirlwind.meteor.wisc.edu/ wxp/nids/nids.html

Images archived for up to a week — http://www.rap.ucar.edu/weather/radar/

\section{WSR-88D Data Information and Archive from the National Climatic Data Center (NCDC)}

NCDC Radar Resources Web site -

http://www.ncdc.noaa.gov/oa/radar/radarresources.html

NEXRAD Inventory Search Tool — http://www.ncdc.noaa.gov/nexradinv/

Radar Data Access Page (download, order, visualize, real time) -

http://www.ncdc.noaa.gov/oa/radar/radardata.html

\section{Free Radar Data Viewing Software}

Unidata Integrated Data Viewer — http://www.unidata.ucar.edu/software/idv/

NOAA's Weather and Climate Toolkit - http://www.ncdc.noaa.gov/oa/wct 